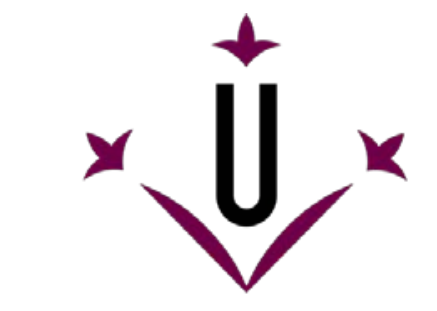

Universitat de Lleida

Document downloaded from:

http://hdl.handle.net/10459.1/68366

The final publication is available at:

https://doi.org/10.1007/s40558-018-0126-7

Copyright

(c) Springer, 2019 


\title{
DOES HOTEL SIZE MATTER TO GET MORE REVIEWS PER ROOM?
}

\begin{abstract}
The number of reviews on websites like TripAdvisor seems to improve hotel ratings and hotel rankings, which favors the perception of hotel quality. Previous studies have focused on the total number of reviews for each hotel, suggesting that increasing the number of reviews could affect hotel ratings. We use a simple index, which is obtained by dividing the number of reviews on TripAdvisor for a given hotel by its number of rooms. This allows identifying the profile of the hotels that are most efficient at generating reviews on this website, which are surprisingly the smallest ones. This index also shows the real level of use of TripAdvisor in each country, without taking into account its population or number of hotels, which are elements that distort the measurement of the popularity of this website.
\end{abstract}

Keywords: reviews, hotel, TripAdvisor, rooms. 


\section{Introduction}

Technology has transformed the tourism industry in recent years, from the traveler's decision process, to the purchase of services, and finally sharing experiences on the Internet. TripAdvisor has taken a leading role in this revolution, especially collecting users' reviews, which are then used by consumers as an information source in travel decision-making.

TripAdvisor recommends hoteliers to encourage their clients to write reviews on its website to improve their score and rankings. In this paper, we focus on quantifying and analyzing the response given by hotels to this insistent demand by TripAdvisor to collaborate in generating reviews. We performed the analysis based on two factors; geographical location, on the one hand, and hotel size, on the other. For this quantification we use a simple index: reviews per room (RR), which is obtained by dividing the number of reviews on TripAdvisor for a given hotel by its number of rooms. The total number of reviews for each hotel would be unsuitable data since such a figure depends mainly on the number of rooms in the hotel, and would not reflect the real degree of use of TripAdvisor by customers. A hotel with 35 rooms and 500 reviews cannot be considered on equal terms with a hotel with 350 rooms and 500 reviews. Any conclusions regarding the degree of participation by its clients on TripAdvisor would be very different in both cases. TripAdvisor probably also takes this into consideration when assessing the number of reviews for a hotel when making its ranking.

For hoteliers, this index can be very useful when establishing comparisons with their competitors for the purpose of increasing the number of reviews to improve their rankings on this popular website. An RR index above or below the competition is a clear indicator of the level of performance in this task.

In the academic field, the use of RR can be appropriate when studies are conducted using TripAdvisor data. It should not be forgotten that in these cases we are talking about a sample of customers (those who fill out the survey) from a universe of guests who visited the hotel. In this context, a higher RR index will correspond to a higher percentage of customers filling in the survey, a more representative sample and greater reliability of the results. This issue is relevant when using this valuable source of information, but no previous research pays attention to this figure. This research attempts to address a current gap in the academic literature regarding the statistical reliability of the data when using hotel reviews.

The only data that TripAdvisor has made public about its popularity by country are somewhat outdated (TripAdvisor 2013a) and focus on the total number of reviews per country. It excludes countries where TripAdvisor has a high level of popularity but a low population and overvalues countries with a high population. By using the geographical data from this study, with the RR index, we will be able to determine the areas and countries with a higher degree of collaboration in TripAdvisor, regardless of the population figures for each country. This could prove useful to academics, who will be able to know where to develop studies based on TripAdvisor with an acceptable level of reliability.

Data from previous studies indicate that big hotel chains (PATA 2014; McEvilly 2015), usually with medium-sized or large hotels (in terms of number of rooms), have implemented specific systems to collect reviews. It would be logical for larger hotels to obtain higher RR, since their technological and organizational capacity should allow them to implement these strategies more efficiently. Through the analysis performed, we can determine if there is a real 
relationship between hotel size and its level of participation on TripAdvisor, exploring possible explanations for the results obtained.

\section{Literature Review}

\subsection{Encouraging TripAdvisor reviews}

TripAdvisor is the world's largest travel site with more than 500 million reviews and a community of 415 million average unique monthly visitors (TripAdvisor 2017). In recent years TripAdvisor has expanded its functionalities and has acquired companies to integrate them into its business group (Yoo et al., 2016). However, TripAdvisor is not only popular among professionals in the tourism industry, its popularity goes further and it has become one of the most visited webpages in the world. Its main website (tripadvisor.com) is ranked $233^{\text {rd }}$ in the world and $69^{\text {th }}$ in the United States, according to the Alexa.com ranking. Moreover, TripAdvisor has 49 different versions, adapted to different countries and languages, which in many cases are among the 100 most popular websites in each country: United Kingdom $\left(44^{\text {th }}\right)$, Spain $\left(70^{\text {th }}\right)$, Italy $\left(37^{\text {th }}\right)$.

TripAdvisor says that its popularity index algorithm is based on three key ingredients: the quality (average rating), quantity (number of reviews) and recentness of reviews (TripAdvisor 2013b). In 2016 TripAdvisor enhanced its popularity ranking algorithm focusing on the quantity and consistency of reviews (TripAdvisor 2016), which means that review volume is now even more important for rankings. It is not easy to increase ratings, but increasing the number of reviews seems more attainable: to encourage customers to write reviews does not require economic investments or significant changes in service protocols. If we do an Internet search using terms like "improve ranking on TripAdvisor" or similar, we systematically see the recommendation to encourage customers to write reviews online (ReviewPro 2015; Bassig 2016; Revinate 2016) as a basic element for improvements in scores and rankings. Although the request by hotels for reviews has its limits, there are appropriate ways to do it that do not include rewarding traveler reviews with discounts or gifts (TripAdvisor 2013c)

TripAdvisor provides a review collection tool called "review express" to send professionallooking emails that encourage guests to write reviews (TripAdvisor 2014a). This kind of strategy to collect more reviews actually works, as reported by Shangri-La Hotels (PATA, 2014) obtaining relevant results in terms of the quantity and recentness of reviews: "Prior to the review collection partnership with TripAdvisor, Shangri-La properties were averaging six reviews each month. Since the partnership began in July 2013, that average has increased $250 \%$ to 21 reviews per property per month. All together, the review collection partnership has driven an average of 534 out of 1930 reviews per month". Moreover, the use of other tools to collect reviews achieves satisfactory results with an average $409 \%$ increase on TripAdvisor review volume (Revinate 2014). Nonetheless, hotels can only send emails to those customers who have provided their address, which is only a percentage of total guests.

Despite an initial period of tension and the lawsuits filed by hotels against TripAdvisor regarding the publication of fake reviews, the relationship among these parties has improved (McEvilly 2015). Wyndham and Accor encourage guests to write reviews on TripAdvisor after their stay; the total number of reviews, average ratings, and recent review content on this 
website are then displayed on each property page. Incentive hierarchies are also adopted by TripAdvisor to motivate users to contribute by awarding them increasingly higher status on the platform (Liu et al., 2016).

\section{2. eWOM in Tourism}

One fundamental principle of consumer behavior refers to the fact that users have the ability to significantly influence each other (Dichter 1966), which has been dubbed "word of mouth" (WOM). Recommendations among users in the tourism sector is a widely discussed topic, even before the existence of Internet (Cohen 1972; Butler 1980). When WOM is propagated via Web 2.0, it is known as 'electronic word of mouth' (eWOM) (Hennig-Thurau et al., 2004) and according to the most cited definition, eWOM is "all informal communications directed at consumers through Internet-based technology related to the usage or characteristics of particular goods and services, or their sellers". The digital equivalent of WOM (Litvin et al., 2008). eWOM is more influential than traditional WOM due to its speed, convenience, ability to reach many, and the lack of human pressure that influences face-to-face communication (Sun et al., 2006).

Online travel reviews are perceived as being similar to the recommendations provided by friends and relatives, and as a more trusted source of information than the official one provided by companies (Wang et al., 2002; Ricci and Wietsma 2006; Yoo et al., 2009; Browning et al., 2013). Such is the significance of user generated content (UGC) that it has forced hoteliers to design organizational strategies of continual vigilance and monitor UGC (Baka 2016). Hotel reviews can identify errors in aspects that are considered important by customers and give rise to most of their complaints (Smyth et al., 2010; Levy et al., 2013).

Hotel reviews are essential in the decision-making process. Seventy-seven percent of travelers usually or always reference reviews before choosing a hotel; $53 \%$ will not commit to booking until they read reviews, and $80 \%$ read at least 6-12 reviews before booking a hotel (TripAdvisor 2014a). Several studies have revealed the impact of reviews when making decisions about hotels (Dellarocas 2003; Gretzel and Yoo 2008; Vermeulen and Seegers 2009; Schuckert et al., 2015).

\subsection{Effects of the volume of reviews, rankings and ratings}

The existing literature confirms that there is a positive relationship between the number of reviews (volume) and the intention to purchase or the increase in sales of different products or services (Godes and Mayzlin 2004; Liu 2006; Dellarocas et al., 2007; Park et al., 2007; Duan et al., 2008; Vermeulen and Seegers 2009; Sparks and Browning 2011; Viglia et al., 2014). It may be seen as a sign of popularity (Zhu and Zhang 2010; Zhang et al., 2013) as many reviews about an item means that a lot of people have purchased it. In the hospitality industry, many reviews could better reflect the reality of hotel quality and may lead to the idea that the more reviews, more guests, and therefore the more popular (Xie et al., 2014).

When travelers search for hotels on Internet, search engines usually provide results in a list, based on some sort of ranking. Information placed high in the list is considered very relevant, but the relevance of the information decreases exponentially when presented in lower positions (Spoerri 2008). Online rating lists are very important and useful in the hospitality 
sector (Filieri and McLeay 2014) and more credible when published by well-known online travel communities like TripAdvisor (Casalo et al., 2015). This is why it is so important for hotels to generate as many reviews as possible on TripAdvisor and, in this way, improve their position in the rankings and lists.

The proliferation of fake reviews as well as press reports and complaints by hoteliers have called into question the credibility of TripAdvisor, whose response to this issue is usually based on the number of reviews "... With over 70 pieces of content coming in every minute occasionally a review or business that does not meet TripAdvisor's guidelines may slip through the crack..." (Legge 2013; BBC 2013). Review trustworthiness and credibility for websites like TripAdvisor are crucial and several researchers have focused on them (Ayeh et al., 2013; Filieri et al., 2015; Gössling et al., 2016). A notion of homophily among online travel consumers can improve the perception of credibility, which, in turn, would encourage TripAdvisor usage in the travel planning context (Ayeh et al., 2013).

Previous studies have demonstrated that "as the number of reviews of a hotel increases, the ratings in these reviews are more positive” (Melián-González et al., 2013). This research, published in an academic journal (Cornell Hospitality Quarterly), was shared by TripAdvisor when publishing a report about it on its own webpage (TripAdvisor 2014b). However, the results are not so convincing when research is about the direct effect of the volume of online reviews on RevPAR growth and sales. A recent study has demonstrated that the volume of reviews has no effect on RevPAR growth for branded chain hotels and a positive effect on RevPAR growth for non-branded chain hotels (Raguseo and Vitari 2017).

It has been demonstrated that ratings provided by websites like TripAdvisor have an impact on number of bookings, possibility of price increment, occupancy levels, ADR, RevPar, etc. Higher customer rating significantly increases the online sales of hotels and a $1 \%$ increase in online customer ratings increases sales per room by up to about $2.6 \%$, depending on the destination (Öğüt and Onur Taş 2012). A 10\% increase in traveler review ratings boosts online bookings by more than 5\% (Ye et al., 2011). A one point increase in a hotel's 100point scale ReviewPro Global Review Index (GRI) leads to a $0.89 \%$ increase in price (ADR), an increase of $0.54 \%$ in occupancy, and a $1.42 \%$ increase in RevPar (Anderson 2012). A onepoint increase on a scale of $1-10$ is associated to an increase in the occupancy rate of $7.5 \%$ (Viglia et al., 2016).

Data provided by TripAdvisor and academic researchers are quite clear about the importance of increasing the number of reviews. It improves hotel ratings and hotel rankings, which favors the perception of hotel quality and, consequently, sales and occupancy rates (Fig. 1). This justifies the hoteliers' interest in improving their efficiency in this task and the need to provide tools that serve as reference in their measurement.

Fig. 1 The influence of the number of hotel reviews. 


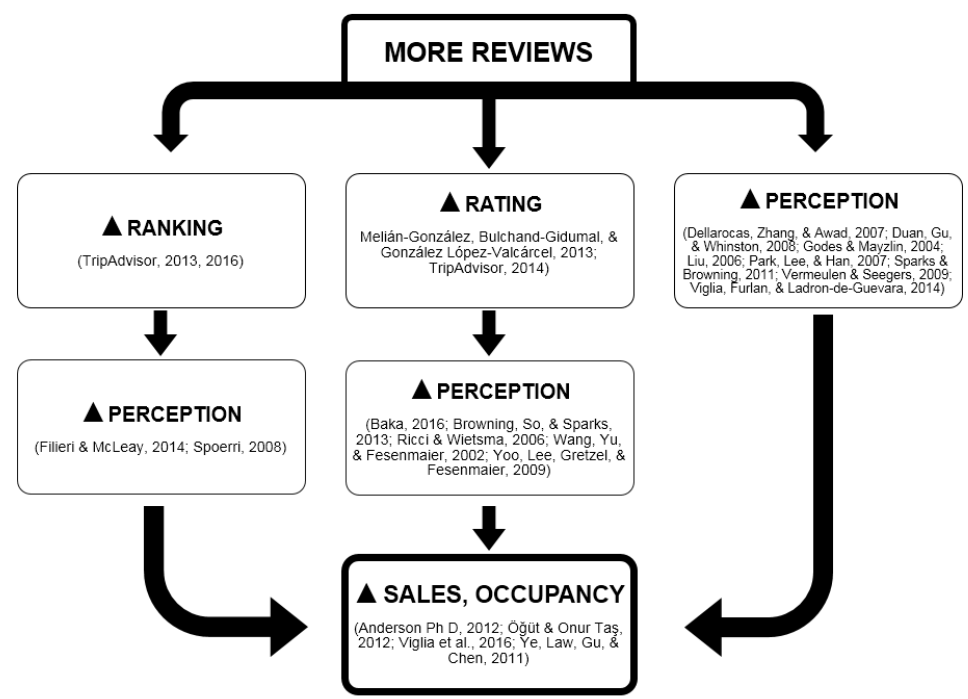

Source: Authors

\section{Methodology}

In this study, we analyze the hotels of the top destinations in the world according to the 2016 TripAdvisor Ranking, dividing them into four regions, namely America (AME), Asia Pacific (ASP), Europe (EUR), and Middle East Africa (MEA), as suggested by Banerjee and Chua (2016) and Martin-Fuentes et al., (2018), and into countries.

In August 2017, we collected the information of hotels on TripAdvisor and the data were downloaded using an automatically controlled web scraper (developed in Python) for TripAdvisor. Some values are missing from the dataset because some managers do not provide hotel category or number of rooms, and some properties have not received any ratings by users. Furthermore, we only work with hotels with at least 30 reviews, thus the sample data were reduced from 20,880 to 17,925 hotels in 373 destinations (66 countries) with a total of 9,021,348 reviews. The data collected were transferred to a CSV file, which allows analyzing the information. The statistical calculations were performed using SPSS software, version 20 .

The number of rooms were grouped into three categories in order to classify hotel size: small (from 1 to 20 rooms), medium (from 21 to 80 rooms) and large (more than 80 rooms), following Briggs et al., 2007,- according to the VisitScotland classification. It is worth mentioning that there is no homogeneous classification of hotel size in the academic literature.

The one-way ANOVA test was performed to determine whether there are any significant differences between the mean RR on TripAdvisor according to hotel size (number of rooms). It tests the null hypothesis:

- $H_{0}: \mu_{1}=\mu_{2}=\mu_{3}$ when $\mu_{n}$ is the mean RR by hotel size $(\mathrm{n}=1,2,3)$. 
- $H_{A}$ : There are two or more group means that are significantly different from each other.

\section{Results}

The descriptive statistics show that the smaller the hotel is, the higher the number of reviews per room it gets on TripAdvisor. Hotels with less than 21 rooms have a much higher mean RR than medium-sized hotels and they multiply the mean RR of the hotels with more than 80 rooms by five, as can be seen in Table 1 .

Table 1. RR by hotel size

\begin{tabular}{rrrr}
\hline $\begin{array}{l}\text { Hotel size } \\
\text { in rooms }\end{array}$ & \multicolumn{2}{l}{ N } & \multicolumn{2}{l}{ Mean } \\
\hline $1-20$ & 2,161 & 17.94 & 20.34 \\
$21-80$ & 7,441 & 7.48 & 8.87 \\
$>80$ & 8,295 & 3.81 & 3.71 \\
\hline Total & 17,897 & 7.04 & 10.41
\end{tabular}

Source: Authors based on data from TripAdvisor

A Levene tests to assess the equality of variances, i.e., homoscedasticity, and a Welch test were conducted to identify different reviews per room on hotel size groups. The results show that there is no homogeneity of variance and the hotel size groups differ significantly in their average RR.

Since the homogeneity of variance assumption was not met, and since there were unbalanced groups because the number of hotels in each category was different, the post hoc follow-up was performed using the statistical Games-Howell test to test the differences between all unique pairwise comparisons. The results concluded that there was a significant effect of mean reviews per room on TripAdvisor for all three hotel categories according to their size ( $p$ $<.001)$.

By regions, small hotels also have a far higher mean RR than the mean RR of medium hotels and large hotels. The difference in mean RR is especially high in hotels from MEA where small hotels have the highest RR and the difference from large hotels is truly high, as can be observed in Table 2.

Table 2. RR by regions

\begin{tabular}{rrrrr}
\hline \multicolumn{1}{l}{ Hotel size in rooms } & \multicolumn{1}{l}{ N } & \multicolumn{1}{l}{ Mean } & \multicolumn{1}{l}{ SD } \\
\hline \multirow{4}{*}{ AME } & $1-20$ & 484 & 18.79 & 20.05 \\
& $21-80$ & 1,336 & 7.50 & 8.27 \\
& $>80$ & 2,143 & 4.60 & 3.84 \\
& Total & 3,963 & 7.31 & 10.00 \\
\hline
\end{tabular}




\begin{tabular}{lrrrr}
\hline & $1-20$ & 379 & 18.29 & 21.09 \\
ASP & $21-80$ & 1,669 & 5.71 & 8.57 \\
& $>80$ & 2,769 & 2.39 & 2.72 \\
& Total & 4,817 & 4.79 & 9.08 \\
\hline \multirow{4}{*}{ EUR } & $1-20$ & 1,219 & 17.27 & 19.59 \\
& $21-80$ & 4,203 & 8.22 & 9.12 \\
& $>80$ & 2,908 & 4.73 & 4.13 \\
& Total & 8,330 & 8.33 & 10.97 \\
\hline \multirow{4}{*}{ MEA } & $1-20$ & 79 & 21.51 & 28.08 \\
& $21-80$ & 233 & 6.67 & 7.71 \\
& $>80$ & 475 & 2.89 & 2.50 \\
Source: Authors based on data from TripAdvisor & &
\end{tabular}

By regions, as the data did not meet the homogeneity of variances assumption, we again conducted the Games Howell post hoc test to determine which pairs of the three hotel categories, according to their size, differed significantly.

The results revealed that there were significant differences among all hotel sizes in all regions.

By regions, the highest RR is in EUR, followed by AME, MEA and ASP, and by countries, analyzing the top ten countries with the most international visitors in 2016, we can see that the highest RR is in Italy followed by the United Kingdom, Turkey, France, Spain, Mexico, the United States, Germany, Russia, and China, as shown in Table 3.

The results of the one-way ANOVA test for the ten countries with most hotels in our dataset, confirm that in most countries, there were significant differences in RR among all hotels sizes, also continuing the tendency that the smaller hotels get a higher average RR than medium and large hotels. The exception are medium and large hotels, which were not significantly different in Germany $(\mathrm{p}=.08)$.

Table 3. RR of the 10 countries with the most international visitors in 2016

\begin{tabular}{lrrr}
\hline & \multicolumn{2}{c}{ Mean } & \multicolumn{1}{c}{ SD } \\
\hline France & 1146 & 8.94 & 10.93 \\
United States & 1517 & 7.01 & 9.27 \\
Spain & 714 & 8.63 & 10.23 \\
China & 803 & 1.95 & 3.29 \\
Italy & 1531 & 12.63 & 15.55 \\
Turkey & 715 & 9.75 & 15.07 \\
Germany & 753 & 3.57 & 4.08 \\
Mexico & 336 & 8.07 & 11.56 \\
United Kingdom & 724 & 11.14 & 9.06 \\
Russia & 303 & 3.16 & 4.00 \\
\hline Source: Authors based on data from TripAdvisor
\end{tabular}

TripAdvisor published the list of the most contributions by countries (TripAdvisor 2013a) with the United States being the top contributor followed by the United Kingdom, Italy, 
Canada, Brazil, France, Australia, Spain, India, and Germany. When comparing this list with the mean RR of our dataset by countries with more than 100 hotels, the results suggest that the highest RR are not related to the most contributions by countries, as can be seen in Table 4 .

Table 4. Countries with the highest mean RR

\begin{tabular}{lrrr}
\hline Country & $\mathrm{N}$ & Mean & $\mathrm{SD}$ \\
\hline Italy & 1,531 & 12.63 & 15.58 \\
Ireland & 143 & 12.60 & 9.03 \\
Cambodia & 224 & 11.97 & 17.06 \\
United Kingdom & 724 & 11.14 & 9.06 \\
Argentina & 311 & 10.25 & 15.30 \\
Turkey & 715 & 9.75 & 15.07 \\
Greece & 246 & 9.52 & 12.52 \\
Netherlands & 288 & 9.49 & 10.79 \\
France & 1,146 & 8.94 & 10.93 \\
Peru & 203 & 8.77 & 9.78 \\
Spain & 714 & 8.63 & 10.23 \\
Vietnam & 543 & 8.63 & 14.45 \\
Chile & 110 & 8.23 & 10.19 \\
Canada & 234 & 8.13 & 8.45 \\
\hline Source: Authors based on data from TripAdvisor
\end{tabular}

Dividing the dataset by hotel category (stars), the results confirm that the lowest categories (1-star hotels) have the highest mean RR, whereas the other categories have a very similar mean RR, as shown in Table 5.

Table 5. RR and rooms by hotel categories

\begin{tabular}{crrr}
\hline $\begin{array}{l}\text { Hotel } \\
\text { category }\end{array}$ & \multicolumn{1}{c}{ N } & RR Mean & RR SD \\
\hline 1 & 273 & 11,26 & 15.33 \\
2 & 1,758 & 6.96 & 12.78 \\
3 & 6,708 & 6.67 & 9.71 \\
4 & 5,823 & 6.80 & 9.19 \\
5 & 2,080 & 6.41 & 8.51 \\
\hline \multicolumn{4}{l}{ Source: Authors based on data from TripAdvisor }
\end{tabular}

A Games-Howell test was conducted (one-way ANOVA) to test the differences between all unique pairwise comparisons as the homogeneity of variance assumption was not met and since there were unbalanced groups because the number of hotels in each category was different. The results concluded that there was a significant effect of mean reviews per room on TripAdvisor for 1 -star hotels with respect to all categories $(p<.001)$, the 1 -star hotels concentrate a higher mean RR, thus we can affirm that 1-star hotels are able to get the attention of their guests to post more reviews per room on TripAdvisor, as shown in Table 5. The other categories do not differ significantly. 
Lastly, we compared the RR according to hotels belonging to chains or independent hotels, and the results confirmed that there was a significant effect of mean reviews per room on TripAdvisor for independent hotels compared with chain hotels $(p<.001)$. Using our sample of 17,925 hotels, we observe that chain hotels are generally larger (189 rooms) than independent hotels (99 rooms). However, belonging to a hotel chain does not seem to be a factor that favors a higher RR, since they present an RR of 5.31 compared to 7.64 for independent hotels, just as expected due to of hotel size differences.

\section{Discussion}

The mean RR differences are statistically significant among all groups of hotels divided into sizes in all regions and in the top ten countries (except Germany). The RR figure observed in Germany is lower than that observed in neighboring European countries, which that can be explained by the importance of HolidayCheck in this country, Poland, Austria and Switzerland. This website offers similar features to those of TripAdvisor and occupies a very similar position in terms of visits (AlexaRanking: Tripadvisor.de=163; HolidayCheck.de=168).

Using the geographical data from this study, we determined that EUR and AME are the two geographical areas where TripAdvisor is most popular, while ASP shows a substantially lower RR level. Using this index we check the real level of the use of TripAdvisor in each country, without population or the number of hotels acting as an element in the distortion of popularity. We identified that the United States is not the country in which this website is most popular. It simply has a medium popularity level (7.0), but a high population, which leads to the highest number of reviews. We identify other countries that do not appear in the list of "top contributors" (TripAdvisor 2013a), because of their low population, but in which the popularity of TripAdvisor among hotel customers is very high, such as Ireland (12.6) and Cambodia (12.0).

Moreover, countries such as the United States, the United Kingdom, France, Italy, Canada, Spain, Brazil, India and Germany, which have the most hotel reviews on TripAdvisor, are not the countries with the highest mean RR. Only Italy, the United Kingdom, France, and Spain coincide with those with the highest traffic on TripAdvisor. The statistical reliability of the results obtained with TripAdvisor data for a country is determined by the RR of its hotels, not by the total number of reviews collected in the country. In this sense, it is necessary to distinguish countries with the top traffic on TripAdvisor because they have a high population from countries with a higher mean RR, which are the countries that receive the largest number of reviews per hotel room and in which we can obtain more reliable conclusions using data from TripAdvisor.

Our research also confirms that 1-star hotels have a significantly different mean RR in respect of the other hotel categories, with 1-star hotels concentrating the highest RR. This could be because the number of rooms is moderately correlated with hotel category (Martin-Fuentes 2016). One-star hotels have fewer rooms than the others, thus small hotels are capable of obtaining a higher RR.

Although number of rooms and number of reviews on TripAdvisor are correlated because more rooms can accommodate more customers that can post more reviews (Molinillo et al., 
2016; Martin-Fuentes 2016) we observe that the largest properties do not capture the attention of guests to post reviews on TripAdvisor because they obtain a smaller RR. For example, the hotel with the highest number of reviews $(16,747)$ in our dataset has 2,560 rooms, leading to a mean RR of only 6.54, which is below the mean for the whole dataset (7.04).

The results confirm that chain hotels are larger (in terms of number of rooms) than independent hotels, that the latter obtain a smaller number of reviews than the former, as confirmed by (Banerjee and Chua 2016), but the RR is lower compared to independent hotels, which leads us to affirm that the systems implemented by large hotel chains to collect reviews (PATA 2014; McEvilly 2015) do not attract the attention of most guests. Conversely, as TripAdvisor points out, "the personalised attention, service and care that they (smaller properties) can provide often results in more of their guests being willing to write reviews" (TripAdvisor 2016).

\section{Conclusions}

The RR index provides a valid indicator of TripAdvisor popularity among visitors to hotels in each destination. It is also a very useful tool to measure the statistical reliability of the data obtained when research is carried out in the academic field using TripAdvisor reviews. The statistical implications of conducting studies using this source of information have not been taken into account in previous academic literature. A higher RR means a higher level of confidence, and hence the statistical reliability of data will be higher. Research using TripAdvisor reviews in Italy $(\mathrm{RR}=12)$ will be much more reliable than research conducted in China $(\mathrm{RR}=2)$.

We might expect that conducting a study on hotels in Shanghai (a Chinese city with 24 million inhabitants and a lot of big hotels) using information from TripAdvisor would provide statistically reliable results if we select hotels with a seemingly high number of reviews (e.g., more than 500). We would probably find as many hotels of these characteristics as in Milan or Florence (Italy). The difference is that in Shanghai hotels, the percentage of guests who complete the TripAdvisor survey is very low, so the statistical reliability of the study will be much lower than if we did it in an Italian city.

The number of reviews for each hotel will mainly depend on the number of TripAdvisor users among its customers, which depends on the total number of customers and is directly related with the number of rooms. The figure should be fairly similar between businesses in the same geographical area, with variations proportional to the number of rooms in each establishment when hotels do not encourage customer reviews. These figures could be increased by hotels that are more active in encouraging customers to write reviews on the website, which TripAdvisor systematically recommends.

Ignoring the recommendations by TripAdvisor to encourage customers to write reviews will result in a low RR and a lower position in the ranking, even if the quality of the services provided is high. Various studies have demonstrated that position in the ranking is somehow related with hotel sales, which is why the collection of reviews should be part of the marketing strategy of any hotel. It is easier and cheaper to encourage customers to write reviews than reduce prices or invest in new services or facilities.

Comentario [1]: He llegit el comentari del teu co-autor. No és el contingut que em causa problemes, sinó la la ubicació del paràgraf 
By analyzing reviews proactively, hotel managers can identify and address operational and service-related issues in order to increase customer satisfaction. Therefore, it is also very interesting for businesses to increase their review databases. The greater the number of reviews recorded, the more reliable the information used for internal analysis will be. It can also be a way to protect against fake negative reviews, since their relative weight will be lower if the establishment has more registered real reviews.

Previous studies seemed to indicate that large hotels, which usually have larger establishments (PATA 2014; McEvilly 2015), are the most active in collecting reviews on TripAdvisor. However, the number of rooms seems to be the only determining factor and hotels belonging to chains have more rooms, so tend to have a lower RR.

We try to explain this striking inverse relationship between the size of the hotel and its ability to collect reviews on TripAdvisor by identifying three possible causes:

a) The effectiveness of actions in small hotels: Imagine a 40-room hotel receiving about 40 reviews per year and a hotel of 400 rooms with 400 reviews per year. The first hotel would only need about 10-20 additional reviews per year to change its RR significantly, whereas the second hotel would need $100-200$ to get the same variation in RR.

b) Personalized customer service: In a small hotel, the number of employees with whom the customer talks is minimum and personal relationships can be established easily. This personalized treatment will help in the process of asking for reviews with a higher level of effectiveness.

c) Actions considered fraudulent by TripAdvisor: The number of reviews may increase because of actions against TripAdvisor's regulations (TripAdvisor 2014c). This spans from writing fake reviews to offering incentives in exchange for reviews or selectively requesting reviews only from guests who have had a positive experience. Any such action will increase the number of reviews and therefore the RR. As indicated in (a), smaller hotels require a lower number of reviews to increase their RR and also fewer fake reviews to increase their score on TripAdvisor. It means that it is easier to increase scores by breaching the rules and it is more difficult to be detected by TripAdvisor.

We cannot determine whether the variations in the RR by hotel size depends only on these three points alone, nor the relative weight of each of them. Further qualitative research, collecting information from hotels with a higher RR and their practices regarding TripAdvisor reviews, could provide an answer to this question. In any case, these data should be taken into account by small hotels, as it can be seen that they seem to have a greater ability to capture reviews despite their smaller size and lack of resources.

This study shows the variability in the levels of participation in TripAdvisor in different countries, but also within the same country, depending on the type of hotel. The use of this $\mathrm{RR}$ index by hotels can serve to obtain a numerical reference that allows them to compare themselves with their competitors in the task of collecting reviews to improve their ranking on TripAdvisor. Furthermore, it helps to set realistic goals for collecting reviews based on the RR of each country. For example, an RR target of 20 for Italy may be reasonable, while it seems an unrealistic figure in countries like Germany or Russia, where TripAdvisor is not so popular. 


\section{Limitations}

Although we use a very large sample (17,925 hotels), it is limited to "top international destinations", which would omit hotels in small towns or cities that are not so popular. It should be noted that the RR figures for each country do not strictly refer to the level of popularity of TripAdvisor in that country, but to the level of popularity among hotel guests. In countries with a high percentage of domestic tourism such as the United States, it could be closely related with the popularity level among locals, but in destinations like the Dominican Republic or Singapore, that RR will depend mainly on the popularity of TripAdvisor among foreign visitors.

RR figures are not accurate in the case of newly opened hotels since TripAdvisor provides the number of reviews since the incorporation of the hotel data sheet to its website, which in most cases is more than 10 years ago. In these new hotels the RR will be consistently low, even if the hotel very actively collects reviews. Nonetheless, the percentage of newly opened hotels will represent a minimum percentage of the sample and is likely to be very similar in the four geographical areas analyzed.

\section{References}

Anderson CK (2012) The Impact of Social Media on Lodging Performance. Cornell Hosp Rep 12:4-11

Ayeh JK, Au N, Law R (2013) “Do We Believe in TripAdvisor?” Examining Credibility Perceptions and Online Travelers' Attitude toward Using User-Generated Content. J Travel Res 52:437-452. doi: $10.1177 / 0047287512475217$

Baka V (2016) The becoming of user-generated reviews: Looking at the past to understand the future of managing reputation in the travel sector. Tour Manag 53:148-162. doi: 10.1016/j.tourman.2015.09.004

Banerjee S, Chua AYK (2016) In search of patterns among travellers' hotel ratings in TripAdvisor. Tour Manag 53:125-131. doi: 10.1016/j.tourman.2015.09.020

Bassig M (2016) 8 Tactics for Improving Your Popularity Ranking on TripAdvisor. ReviewTrackers. https://www.reviewtrackers.com/8-tactics-improving-popularity-ranking-tripadvisor/. Accessed 18 January 2018

BBC (2013) TripAdvisor removes fake Brixham restaurant Oscar's. BBC News. http://www.bbc.com/news/uk-england-devon-23504081. Accessed 18 January 2018

Briggs S, Sutherland J, Drummond S (2007) Are hotels serving quality? An exploratory study of service quality in the Scottish hotel sector. Tour Manag 28:1006-1019. doi: 10.1016/j.tourman.2006.08.015

Browning V, So KKF, Sparks B (2013) The influence of online reviews on consumers' attributions of service quality and control for service standards in hotels. J Travel Tour Mark 30:23-40

Butler RW (1980) The concept of a tourist area cycle of evolution: implications for management of resources. Can Geogr Géographe Can 24:5-12 
Casalo L V., Flavian C, Guinaliu M, Ekinci Y (2015) Do online hotel rating schemes influence booking behaviors? Int J Hosp Manag 49:28-36

Cohen E (1972) Toward a sociology of international tourism. Soc Res 164-182

Dellarocas C (2003) The digitization of word of mouth: Promise and challenges of online feedback mechanisms. Manag Sci 49:1407-1424

Dellarocas C, Zhang X (Michael), Awad NF (2007) Exploring the value of online product reviews in forecasting sales: The case of motion pictures. J Interact Mark 21:23-45. doi: 10.1002/dir.20087

Dichter E (1966) How word-of-mouth advertising works. Harv Bus Rev 44:147-160

Duan W, Gu B, Whinston AB (2008) The dynamics of online word-of-mouth and product sales-An empirical investigation of the movie industry. J Retail 84:233-242. doi: 10.1016/j.jretai.2008.04.005

Filieri R, Alguezaui S, McLeay F (2015) Why do travelers trust TripAdvisor? Antecedents of trust towards consumer-generated media and its influence on recommendation adoption and word of mouth. Tour Manag 51:174-185. doi: 10.1016/j.tourman.2015.05.007

Filieri R, McLeay F (2014) E-WOM and accommodation: An analysis of the factors that influence travelers' adoption of information from online reviews. J Travel Res 53:44-57

Godes D, Mayzlin D (2004) Using Online Conversations to Study Word-of-Mouth Communication. Mark Sci 23:545-560 . doi: 10.1287/mksc.1040.0071

Gössling S, Hall CM, Andersson A-C (2016) The manager's dilemma: a conceptualization of online review manipulation strategies. Curr Issues Tour 1-20

Gretzel U, Yoo KH (2008) Use and Impact of Online Travel Reviews. In: O'Connor P, Höpken W, Gretzel U (eds) Information and Communication Technologies in Tourism. Springer Vienna, Vienna, pp 35-46

Hennig-Thurau T, Gwinner KP, Walsh G, Gremler DD (2004) Electronic word-of-mouth via consumeropinion platforms: What motivates consumers to articulate themselves on the Internet? J Interact Mark 18:38-52. doi: 10.1002/dir.10073

Legge (2013) Glasgow homeless hostel makes Tripadvisor's top 100 UK hotels after “jokers" post comedy reviews. The Independent. http://www.independent.co.uk/news/uk/homenews/glasgow-homeless-hostel-makes-tripadvisors-top-100-uk-hotels-after-jokers-postcomedy-reviews-8588432.html. Accessed 18 January 2018

Levy SE, Duan W, Boo S (2013) An analysis of one-star online reviews and responses in the Washington, DC, lodging market. Cornell Hosp Q 54:49-63

Litvin SW, Goldsmith RE, Pan B (2008) Electronic word-of-mouth in hospitality and tourism management. Tour Manag 29:458-468 . doi: 10.1016/j.tourman.2007.05.011

Liu X, Schuckert M, Law R (2016) Online incentive hierarchies, review extremity, and review quality: Empirical evidence from the hotel sector. J Travel Tour Mark 33:279-292 
Liu Y (2006) Word of mouth for movies: Its dynamics and impact on box office revenue. J Mark 70:74-89

Martin-Fuentes E (2016) Are guests of the same opinion as the hotel star-rate classification system? J Hosp Tour Manag 29:126-134. doi: 10.1016/j.jhtm.2016.06.006

Martin-Fuentes E, Fernandez C, Mateu C, Marine-Roig E (2018) Modelling a grading scheme for peerto-peer accommodation: Stars for Airbnb. Int J Hosp Manag 69:75-83. doi: 10.1016/j.ijhm.2017.10.016

McEvilly B (2015) How Online Review Sites Are Affecting Your Hotel. In: Hosp. Net. https://www.hospitalitynet.org/opinion/4070901.html. Accessed 18 January 2018

Melián-González S, Bulchand-Gidumal J, González López-Valcárcel B (2013) Online customer reviews of hotels: As participation increases, better evaluation is obtained. Cornell Hosp Q 54:274283

Molinillo S, Ximénez-de-Sandoval JL, Fernández-Morales A, Coca-Stefaniak A (2016) Hotel Assessment through Social Media: The case of TripAdvisor. Tour Manag Stud 12:15-24 . doi: 10.18089/tms.2016.12102

Öğüt H, Onur Taş BK (2012) The influence of internet customer reviews on the online sales and prices in hotel industry. Serv Ind J 32:197-214 . doi: 10.1080/02642069.2010.529436

Park D-H, Lee J, Han I (2007) The Effect of On-Line Consumer Reviews on Consumer Purchasing Intention: The Moderating Role of Involvement. Int J Electron Commer 11:125-148 . doi: 10.2753/JEC1086-4415110405

PATA (2014) Shangri-La Hotels and Resorts Study Shows Review Collection Partnership with TripAdvisor Leads to More Reviews and Higher Ratings. https://www.pata.org/shangri-lahotels-and-resorts-study-shows-review-collection-partnership-with-tripadvisor-leads-tomore-reviews-and-higher-ratings/. Accessed 18 January 2018

Raguseo E, Vitari C (2017) The Effect of Brand on the Impact of e-WOM on Hotels' Financial Performance. Int J Electron Commer 21:249-269

ReviewPro (2015) TripAdvisor Partnership to Help Hotels Boost Review Volume. https://www.reviewpro.com/blog/reviewpro-expands-tripadvisor-partnership-to-helphotels-boost-review-volume/. Accessed 18 January 2018

Revinate (2016) 7 Ways to Improve TripAdvisor Performance. https://www.revinate.com/blog/2016/02/7-ways-to-improve-tripadvisor-performance/. Accessed 18 January 2018

Revinate (2014) Revinate Announces Results of TripAdvisor Review Collection Partnership. https://www.revinate.com/blog/2014/10/revinate-announces-results-tripadvisor-reviewcollection-partnership/. Accessed 18 January 2018

Ricci F, Wietsma RT (2006) Product reviews in travel decision making. Inf Commun Technol Tour 2006 296-307

Schuckert M, Liu X, Law R (2015) Hospitality and Tourism Online Reviews: Recent Trends and Future Directions. J Travel Tour Mark 32:608-621 . doi: 10.1080/10548408.2014.933154 
Smyth PCB, Wu G, Greene D (2010) Does tripadvisor makes hotels better. Derek Greene Sch Comput Sci Inform Univ Coll Dublin Belfield

Sparks BA, Browning V (2011) The impact of online reviews on hotel booking intentions and perception of trust. Tour Manag 32:1310-1323

Spoerri A (2008) Authority and ranking effects in data fusion. J Am Soc Inf Sci Technol 59:450-460 . doi: 10.1002/asi.20760

Sun T, Youn S, Wu G, Kuntaraporn M (2006) Online word-of-mouth (or mouse): An exploration of its antecedents and consequences. J Comput-Mediat Commun 11:1104-1127

TripAdvisor (2013a) TripAdvisor Contributors. https://www.tripadvisor.com/InfoCentera_ctr.2013highlights. Accessed 18 January 2018

Tripadvisor (2017) Media Center, About us. https://tripadvisor.mediaroom.com/US-about-us. Accessed 18 January 2018

TripAdvisor (2013b) TripAdvisor Popularity Ranking: Key Factors and How to Improve. In: TripAdvisor Insights. https://www.tripadvisor.com/TripAdvisorInsights/n684/tripadvisor-popularityranking-key-factors-and-how-improve. Accessed 18 January 2018

TripAdvisor (2016) Everything You Need to Know About the TripAdvisor Popularity Ranking Algorithm. In: TripAdvisor Insights.

https://www.tripadvisor.com/TripAdvisorInsights/n2701/everything-you-need-know-abouttripadvisor-popularity-ranking-algorithm. Accessed 18 January 2018

TripAdvisor (2013c) The TripAdvisor Incentives Policy: Why Rewarding Traveller Reviews Is Against The Rules. In: TripAdvisor Insights.

https://www.tripadvisor.co.uk/TripAdvisorInsights/n692/tripadvisor-incentives-policy-whyrewarding-traveller-reviews-against-rules?language=en-GB. Accessed 15 Jan 2018

TripAdvisor (2014a) 24 insights to shape your TripAdvisor strategy. In: TripAdvisor Insights. https://www.tripadvisor.co.uk/TripAdvisorlnsights/n2120/24-insights-shape-yourtripadvisor-strategy?language=en-GB. Accessed 18 January 2018

TripAdvisor (2014b) More reviews, higher rating. https://www.tripadvisor.com/TripAdvisorInsights/n2086/more-reviews-higher-rating. Accessed 18 January 2018

TripAdvisor (2014c) What is considered fraud? In: TripAdvisor Help Cent. http://www.tripadvisorsupport.com/hc/en-us/articles/200615037-What-is-consideredfraud-. Accessed 18 January 2018

Vermeulen IE, Seegers D (2009) Tried and tested: The impact of online hotel reviews on consumer consideration. Tour Manag 30:123-127 . doi: 10.1016/j.tourman.2008.04.008

Viglia G, Furlan R, Ladrón-de-Guevara A (2014) Please, talk about it! When hotel popularity boosts preferences. Int J Hosp Manag 42:155-164 . doi: 10.1016/j.ijhm.2014.07.001

Viglia G, Minazzi R, Buhalis D (2016) The influence of e-word-of-mouth on hotel occupancy rate. Int J Contemp Hosp Manag 28:2035-2051 
Wang Y, Yu Q, Fesenmaier DR (2002) Defining the virtual tourist community: implications for tourism marketing. Tour Manag 23:407-417

Xie KL, Zhang Z, Zhang Z (2014) The business value of online consumer reviews and management response to hotel performance. Int J Hosp Manag 43:1-12 . doi: 10.1016/j.ijhm.2014.07.007

Ye Q, Law R, Gu B, Chen W (2011) The influence of user-generated content on traveler behavior: An empirical investigation on the effects of e-word-of-mouth to hotel online bookings. Comput Hum Behav 27:634-639 . doi: 10.1016/j.chb.2010.04.014

Yoo K-H, Lee Y, Gretzel U, Fesenmaier DR (2009) Trust in travel-related consumer generated media. Inf Commun Technol Tour 2009 49-59

Yoo K-H, Sigala M, Gretzel U (2016) Exploring TripAdvisor. In: Egger R, Gula I, Walcher D (eds) Open Tourism: Open Innovation, Crowdsourcing and Co-Creation Challenging the Tourism Industry. Springer Berlin Heidelberg, Berlin, Heidelberg, pp 239-255

Zhang Z, Zhang Z, Wang F, Law R, Li D (2013) Factors influencing the effectiveness of online group buying in the restaurant industry. Int J Hosp Manag 35:237-245 . doi: 10.1016/j.ijhm.2013.06.012

Zhu F, Zhang X (2010) Impact of online consumer reviews on sales: The moderating role of product and consumer characteristics. J Mark 74:133-148 